\title{
La identificación del imaginario colectivo. El caso de los alumnos españoles de Comunicación en el marco del EEES
}

\author{
Carmen GaOna PisOnero \\ Universidad Rey Juan Carlos de Madrid \\ carmen.gaona@urjc.es \\ Juan-Francisco ToRREgrosa CARMONA \\ Universidad Rey Juan Carlos de Madrid \\ juanfrancisco.torregrosa@urjc.es
}

Recibido: 06/11/2012

Aceptado: 23/01/2013

\section{Resumen}

El presente trabajo se acerca al imaginario colectivo que caracteriza a los jóvenes universitarios españoles del área de Comunicación que cursan grados adaptados al Espacio Europeo de Educación Superior (EEES). Para ello, se preguntó directamente a los propios alumnos, con el objetivo de conocer sus opiniones y la autoconstrucción identitaria que realizan. La tecnología, el género, la diversidad cultural o la religión son algunos de los temas que centran el interés de la investigación llevada a cabo con los estudiantes en el aula.

Palabras clave: Imaginario colectivo, alumnos españoles.

\section{The Identification of the Collective Imagination. The Case of Spanish Students of Communication in the Context of the EHEA}

\begin{abstract}
This paper approaches the collective imagination that characterizes young Spanish college students who attend Communication degrees adapted to the European Higher Education Area (EHEA). This is done by directly asking the students, in order to collect opinions and performe self identity. Technology, gender, religion or cultural diversity are some of the issues that focus the interest of the research conducted with students in the classroom.
\end{abstract}

Keywords: Collective imagination, Spanish students.

\section{Referencia normalizada}

GAONA PISONERO, Carmen y TORREGROSA CARMONA, Juan Francisco (2013): "La identificación del imaginario colectivo. El caso de los alumnos españoles de Comunicación en el marco del EEES". Estudios sobre el Mensaje Periodístico. Vol. 19, Núm. especial marzo, págs.: 197-205. Madrid, Servicio de Publicaciones de la Universidad Complutense.

Sumario: 1. Introducción. 2. Metodología; 2.1. Aproximación teórica a la memoria estética y al sentido social continuum. 3. Desarrollo. Autoconstrucción de las alteridades; 3.1. Delimitación emic de la memoria estética; 3.1.1. Elementos de la memoria estética de un "grupo de jóvenes españoles urbanos"; 3.2. "Delimitación emic del sentido social continuum". 4. Conclusiones. 5. Referencias bibliográficas.

\section{Introducción}

Las aulas universitarias del área de Comunicación, en pleno proceso de adaptación al Espacio Europeo de Educación Superior (EEES), son espacios de formación teórica y humanística del joven universitario, al que no sólo se le plantean dudas epistemológicas, sino también sobre su construcción identitaria. Que el alumno se enfrente a 
ambos planteamientos repercutirá en su futura práctica como profesional de la comunicación. Una propuesta dentro de esta estrategia de reflexión identitaria es la "alteridad cognitiva académica". Por este concepto entendemos los procesos de reflexión sobre nosotros mismos, pero provocados desde la docencia. Se concibe la "alteridad" como condición esencial en la producción de pensamiento: conocemos desde nosotros mismos en la forma de yo como un alter cognoscitivo. En esta nueva dinámica lo que se inserta es que el docente provoque esa curiosidad del alumno por conocerse e investigarse como persona y futuro profesional. Por otro lado, se orienta esa "alteridad cognitiva académica" hacia un aspecto imprescindible tanto del ámbito de la identidad como del espacio público: el imaginario colectivo/social. Tal y como decía Habermas, el "espacio público" es, en cierto modo, la práctica de la "razón comunicacional", pero para reincorporarla realmente en nuestra práctica cotidiana debemos empezar antes por redescubrirla. Nuestra propuesta es redescubrir esa "razón comunicacional", de la mano de la construcción/identificación que cada alumno debe hacer de dos de los elementos constitutivos de su imaginario social: el sentido social "continuum" y la memoria estética. Se hará una exposición teórica de estos elementos, para después presentar experiencias de las principales reconstrucciones que los alumnos primero de Grado Periodismo y Grado Comunicación Audiovisual (Universidad Rey Juan Carlos) han hecho de su imaginario colectivo; reconstrucción elaborada desde esa doble vertiente a la que hemos aludido: como ciudadano y como futuro profesional. Nos nutrimos constantemente del imaginario social tanto a lo largo de las pequeñas acciones cotidianas en nuestros múltiples escenarios sociales como también en nuestras construcciones mediáticas, sin ser conscientes de ello, quedando únicamente verbalizado el imaginario social en ciertos discursos academicistas y políticos. En ese ejercicio continuo de hermeneusis sobre la realidad social, abordamos representaciones sociales desde unos referentes culturales, como cuando el individuo se enfrenta a la comprensión de la realidad descrita en un texto: "los lectores aparecen como poseedores de conocimientos y competencias culturales adquiridos en experiencias sociales previas y que son actualizados y utilizados en el momento de la interpretación. Por otra parte, la relación entre una forma cultural y el sujeto que se la apropia no se asemeja a la de un lector aislado y un texto, porque el individuo ha sido formado culturalmente, porque su actividad es social y porque ésta tiene lugar en determinados contextos en los que se halla disponible un cierto rango de discursos (interdiscursividad)" (Ariño. 1997: 190).

Establecemos como objetivo principal de este ejercicio académico ayudar en una educación hacia individuos libres, con criterios y opiniones propias, con un compromiso con la comunicación y en última instancia con nuestra sociedad.

\section{Metodología}

El imaginario social, -también llamado conciencia colectiva, o imaginario colectivo-, es una pieza clave en toda reproducción de sentidos, puesto que el imaginario nos permite funcionar socialmente, en nuestro día a día. Pero lo más importante, el imaginario colectivo nos permite construirnos, a ritmo lento, como individuos sociales poseedores de una cultura. Sin eliminar la subjetividad que aflora en cada ciudadano, 
haremos una delimitación teórica teniendo en cuenta que es un concepto en deconstrucción sistémica constante. El imaginario social viene a dotar de sentido social a las sociedades humanas como creación ontológica de un modo de ser "sui generis". Siguiendo a Olivier Fresard, designa también al mundo singular una y otra vez creado por una sociedad como su mundo propio; el imaginario social es un "magna de significaciones" creadas de forma intersubjetiva y materializadas en instituciones y prácticas cotidianas concretas. ¿Quiénes son sus creadores? Basta remitirnos al título del trabajo de Fresard (2005) "El imaginario social o la potencia de inventar de los pueblos".

Tras esta breve delimitación teórica, proponemos una segunda estrategia conceptual para seguir aproximándonos a la comprensión de un imaginario social: la presentación de algunos de sus elementos. Dicha presentación contribuirá a la visibilización y comprensión del imaginario social que existe en ese nivel subyacente, que no vemos, que no podemos palpar, pero que forma parte de nuestra realidad social, y que también está sujeto a transformaciones y al impacto de las Nuevas Tecnologías. Como principales elementos integrados en el imaginario colectivo, y por consiguiente también conectados con la cultura, tenemos una propuesta de categorización compuesta por cinco elementos interrelacionados: 1) la memoria colectiva; 2) los roles y normas sociales; 3 ) un mapa del espacio social; 4) el orden moral o metafísico, y 5) el sentido social "continuum". Nos limitaremos a exponer una delimitación teórica de los dos elementos utilizados en nuestra práctica académica: el sentido social "continuum" y la memoria estética.

\subsection{Aproximación teórica a la memoria estética y al sentido social continuum}

Para entender la memoria estética, debemos antes hacer una presentación de la "memoria colectiva", pues la memoria estética es una subcategoría de ésta. La memoria colectiva no es una estructura cognitiva aislada de la práctica social, sino que es uno de los elementos constitutivos del nuestra cotidianeidad. ¿Qué pasaría si se borrasen todos nuestros recuerdos? Rápidamente podemos decir que crearíamos nuevos recuerdos, pero durante un largo periodo de tiempo todos nuestros egos trascendentales serían anónimos; desconocidos caminando de forma inevitable hacia el precipicio.

Otra de las características de la aplicabilidad social de la memoria colectiva -además de salvarnos del abismo y del mayor de los relativismos culturales posibles-, es su entropía interna. La memoria colectiva es entrópica-proyectiva: está cimentada en el pasado, alimenta el presente y posibilita el diseño y configuración de los futuros sociales, desde sorpresivos sujetos e imprevisibles contextos. Como una de las acciones de esa memoria, mencionamos la construcción narrativa, su descripción densa -desde la óptica de Clifford Geertz- de nuestro común pasado/presente y futuro, con ese potencial entrópico/proyectivo y mediático, y todo ello en medio de una gran carga dialéctica. "Si la cultura no es un mero objeto de análisis, tampoco es un cuerpo unificado de símbolos a los que podemos dar una interpretación. Cultura significa contestación. También representación y explicación de esos procesos de contestación tanto como de lo analizado" (Clifford, 1991: 50).

Desde la construcción narrativa, la memoria colectiva es el relato de cómo hemos llegado a ser lo que somos, de cómo contamos nuestra historia, de ahí que también se 
le denomine memoria histórica, y de hecho, en múltiples ocasiones, se confunde la memoria colectiva con la histórica. Sin embargo, la memoria histórica se constituye como una subcategoría de la memoria colectiva; en una diversidad de "memorias colectivas". Por consiguiente: toda memoria histórica es memoria colectiva, pero no toda memoria colectiva es memoria histórica; la memoria histórica está integrada en la memoria colectiva, en esa tipología de "memorias". Hablamos de distintas subcategorías de memoria colectiva, tales como la memoria histórica, junto con la memoria audiovisual (las representaciones sociales sobre las principales películas, series, documentales y demás contenidos audiovisuales que poseen y comparten un grupo cultural concreto); la memoria sensitiva (en íntima conexión con nuestros cinco sentidos, de este modo tenemos grabados en nuestra mente colectiva olores, sabores, músicas y sonidos); la memoria arquitectónica (el conjunto de monumentos y espacios arquitectónicos compartidos por una comunidad interpretativa), y la memoria estética, entre otras subcategorías más. Tras la delimitación conceptual de la memoria colectiva, como una memoria entrópica/proyectiva, conviene hacer dos puntualizaciones. En primer lugar, aclarar cómo esa memoria entrópica/proyectiva no está encorsetada dentro de unos límites culturales y unos límites de sentidos ya existentes en el imaginario social. Esto último marcaría un ritmo determinista de la reproducción social, es decir, no podremos ser nunca más que algo parecido, común de lo que hemos sido y somos. Por consiguiente, ser una sucesión de "continuums", cuando "lo que seré" y "lo que seremos", está sujeto a unas leyes socioculturales, a la teoría del caos social, pero abocado irremediablemente a un caos creativo, a una especie de improvisación cultural, íntimamente ligada y conectada a la creatividad humana.

Las memorias del imaginario colectivo no son infinitas en su cuantificación, pero sí en la construcción de sus sentidos, además de que constantemente quedan invisibilizadas. Por ejemplo, todo grupo comunicativo construye uno de los temas iconográficos de mayor exigencia social: la figura de la mujer. Ésta última estaría integrada en la memoria estética. En la construcción de época de la figura de la mujer, se hace uso de "imágenes" sedimentadas en el imaginario social de referencia, a lo que debemos evidentemente sumarle la poderosa y creciente influencia mediática. La selección de dichas imágenes puede estar hecha desde diferentes ópticas: renacentista, barroca, impresionista o cubista, pongamos por caso. Pero independientemente de su configuración, ésta va re-significándose a lo largo del tiempo. A su vez, conviviendo con esa renovación de época de la figura de la mujer, coexisten en la memoria estética unos principios universales de lo femenino, construidos etnocéntricamente en un modelo sincrónico y platónico. Un ejemplo es el "eterno femenino" descrito por Goethe, en donde confluye la representación simbólica de la madre y la amada en un principio universal que remite a la propia Eva.

Un último aspecto destacable de la memoria colectiva es su marcado carácter mediático tanto en su producción como en su difusión. Si bien al inicio señalábamos el nivel subyacente en que se sitúa todo imaginario social y por consiguiente de la localización de muchos de sus elementos, no menos cierto es que la visualización de éstos en la práctica social cotidiana hace uso de distintos espacios materiales, siendo los medios en la actualidad uno de sus principales agentes de mediación simbólica. Se 
debe puntualizar, al abordar este tipo de cuestiones, que tanto la memoria colectiva como la memoria histórica no son autoría exclusiva y directa de los historiadores. Éstos no son los únicos responsables de recuperar y elaborar el discurso de nuestra historia. Nuestras memorias se construyen desde el aporte de diversos actores y agentes sociales: historiadores, periodistas, cineastas, escritores, artistas, empresas, medios de comunicación, gobiernos, etc.

Para el caso de los agentes sociales, nos estamos refiriendo tanto a las distintas academias dentro de un ámbito de producción científica como a otros espacios al margen de ese ámbito academicista, como son por ejemplo los blogs, las nuevas redes sociales y los nuevos espacios virtuales: Second Life, YouTube, Tuenti y similares. Entre los lugares y escenarios de la memoria, Internet aparece indiscutiblemente como el nuevo espacio central. Respecto a nuestro segundo elemento del imaginario colectivo, sentido social "continuum", gracias a éste, el imaginario social nos otorga, además, una concepción más amplia de la situación: no solamente tenemos las bases para entender y establecer relaciones sociales presentes, sino que desde el "imaginario social" entendemos la relación que mantenemos o hemos mantenido entre nosotros como pertenecientes a una comunidad interpretativa concreta-, así como con el poder, desde una perspectiva de pasado, presente y futuro. Es decir, nuestra relación con otros pueblos y naciones; nuestra relación con la historia, nuestra valoración o enjuiciamiento de nuestra "memoria colectiva".

\section{Desarrollo. Autoconstrucción de las alteridades}

Uno de los primeros pasos que los alumnos/as debían dar era delimitar el grupo identitario en el que se inscriben, y desde el que interpretan los elementos demandados del imaginario social; en definitiva tenían que describir su "comunidad interpretativa". Los sentidos que conforman un imaginario son compartidos por amplios grupos de personas, incluso dicha posesión simbólica puede tener su correspondencia con todo un grupo cultural, o en su caso máximo con todo un grupo nacional concreto; pero en todos los casos nombrados, el "imaginario social" se relaciona con una comunidad interpretativa concreta. A su vez, esta comunidad interpretativa se entremezcla con otras comunidades interpretativas, y esto es posible en tanto que ambas tienen sentidos compartidos.

En nuestra práctica era de vital importancia que nuestros jóvenes hicieran un primer ejercicio de auto-interrogarse y consensuar luego después en grupo la comunidad interpretativa a la que libremente se adscriben. Comentamos cómo nos sorprende que siempre que se propone esta práctica, el primer paso suponga una dificultad para el alumno/a. Ello viene motivado por varias razones, entre las cuales está la falta de ejercicio cognitivo identitario, es decir, tal y como los estudiantes nos confesaban, no es algo habitual el plantearse aspectos relativos a su identidad. Como primeras reflexiones sobre los resultados de este "ejercicio", es significativo que esa falta de práctica se traduzca en delimitaciones macro, y en múltiples ocasiones reducidas a dos o tres palabras. Como primeras respuestas teníamos delimitaciones del tipo: "comunidad de jóvenes españoles". Ante la insistencia de delimitar y seguir auto-interrogándose en este "ejercicio cognitivo identitario", llegamos a delimitaciones de este tipo: "La co- 
munidad interpretativa en la que nos situamos sería una sociedad española, joven, urbana, universitaria, liberal y en permanente contacto con la tecnología" (5 alumnas y 1 alumno de Primero de Grado Comunicación Audiovisual). Es interesante insertar en el texto las explicaciones que daban a cada uno de los calificativos empleados:

- "Pues bien, como sociedad española entendemos aquellas personas que conviven en España y que comparten sus costumbres y rituales".

- "Por jóvenes entendemos un rango de edad, desde los nacidos en los 90 hasta la actualidad".

- "Por personas urbanas a aquellos que vivan en la ciudad, que estén familiarizados con la vida en la ciudad aunque vivan en las afueras de ésta".

- "Por personas pertenecientes a una comunidad interpretativa liberal, entendemos que éstas no tienen prejuicios, y que saben tolerar cualquier ideología y respetarla".

- "Por último las personas que están en continuo contacto con la tecnologías, serían aquellas que usan en su día a día la tecnología (móvil, Internet, ordenador, iPod, etc.) y que hacen buen uso de ella".

\subsection{Delimitación emic de la memoria estética}

El siguiente paso que tenían que abordar en la práctica era categorizar de una forma consensuada en su grupo de trabajo (elegido libremente), "sentidos" (símbolos) que constituyeran parte de los dos elementos ya referenciados: de su sentido social "continuum" y de su memoria estética. A continuación exponemos algunos de los elementos que más se han repetido a lo largo del ejercicio, desde una delimitación completamente "emic", es decir, reproduciendo las propias narraciones y descripciones elaborados por los jóvenes estudiantes.

\subsubsection{Elementos de la memoria estética de un "grupo de jóvenes españoles ur- banos"}

Nos sorprende un grupo constituido por cinco alumnas de entre 19 y 23 años, y un alumno de 19 años, que inicia su listado de elementos constitutivos de su memoria estética aludiendo a la "mentalidad metrosexual", trascribiendo a continuación su comentario: "La mentalidad metrosexual que conlleva a esos hombres que rechazan la idea de "hombre macho", peludo y que tienen un alto cuidado de su cuerpo como el uso de cremas, operaciones, depilaciones... entre otras cosas". Dentro de esta misma línea de relacionar elementos estéticos corpóreos con la memoria estética, reproducimos un listado de elementos nombrados a lo largo de la práctica de forma generalizada:

- "Por la búsqueda de los actuales ideales de belleza tanto masculina como femenina, se ha creado una nueva técnica de depilación para la permanente ausencia de pelo en el cuerpo (laser), que a su vez ésta está al alcance de una gran parte de la población".

- "Las chicas que llevan el pelo corto simbolizan una mayor independencia del hombre, así como la búsqueda de cosas diferentes y sobre todo la seguridad en sí misma". 
- “Los estampados y colores llamativos simbolizan a aquella década de los 80's y la movida madrileña y que en repetidas ocasiones vuelvan de moda y que no está vista como "hortera" sino como una forma de rememorar esa época".

- "Las "Converse" ("All Star") antiguamente eran de pobres, con pocas posibilidades adquisitivas y actualmente se ha aumentado su precio por influencia de la moda".

- "Antes la ropa negra se usaba como símbolo de elegancia o luto, y actualmente con la creación de las tribus urbanas, se ha convertido en un símbolo de identidad como los tejanos".

- "La camisa de cuadros era para los hombres y ahora la usan las mujeres y pertenece a la moda".

De forma anecdótica, un grupo, alejándose de esta correlación de elementos estéticos de la vestimenta y de las estéticas corpóreas, señala como elementos de su memoria estética el "gotelé": "El "gotelé" marcó una etapa en el estilo decorativo de una casa, y ahora, en cambio se usa más colores lisos, sin "gotelé" (Alumnos de Primero de Grado Comunicación Audiovisual). Podríamos seguir con ese listado de elementos constitutivos de la memoria estética de los "jóvenes españoles", tal y como es enunciado en la práctica y constataríamos una constante y una gran ausencia. Como tendencia reiterada, hay que comentar cómo los diferentes "sentidos" de esa memoria estética hacen mención a aspectos de la moda, y aspectos corpóreos, pero no aluden a una construcción simbólica que conecte con otros niveles de esta memoria estética, como podrían ser una mayor profundización en el lenguaje de los colores, de las formas geométricas, de la iconografía pictórica. Así por ejemplo no se aludió en ningún momento a obra alguna de nuestro gran legado pictórico. Este comentario no se hace a modo de crítica, sino con el fin de constatar las ausencias significativas. Objeto de otra reflexión sería comprender la causalidad o causalidades de dichas ausencias.

\section{2. "Delimitación emic del sentido social continuum"}

Este elemento planteó una doble dificultad para el alumno. Por un lado la intangibilidad de todo el imaginario social y por ende de sus elementos aparece doblemente palpable en el sentido social "continuum", y más cuando los alumnos lo relacionan -aunque de forma errónea-, con una categorización de valores, siendo estos últimos para nuestros estudiantes de una gran complejidad epistemológica. No obstante, exponemos algunos de los "valores" señalados y explicados, que no definidos, por nuestros jóvenes estudiantes, si bien reiteramos que en esta práctica, en una primera instancia, no se intentaba lograr una excelente precisión sino instar a los alumnos a la reflexión y construcción intersubjetiva: un primer ejercicio de práctica comunicativa. Sirva de muestra de esa práctica algunos de los elementos del sentido social "continuum" delimitados de forma émica:

-Educación menos autoritaria y más respetuosa: "En la educación ya sea pública (la recibida en el colegio) o privada (la recibida en casa), había más autoridad antes que ahora, antes te "daban un azote" y no pasaba nada y ahora sí, en referencia al respeto que se tiene sobre ti." 
-Nueva construcción del género: "Hace ya 35 años que es tradición hacer manifestaciones en pro del orgullo homosexual. En España no hace tantos años pero aun así significa un punto de inflexión a favor de la igualdad entre homosexuales y heterosexuales. Como consecuencia cambian las relaciones que mantenemos entre nosotros".

-Diversidad cultural: "El incremento del número de inmigrantes que ha recibido nuestro país en los últimos años ha modificado las relaciones con otros pueblos. Tanto para bien como para mal. Por un lado un pensamiento en contra de estas personas y por otro de apoyo hacia ellos y de defensa de su situación".

-Salud y tabaco: "Desde hace unos años se considera el tabaco como algo totalmente perjudicial, no como sus inicios, cuando todo el mundo fumaba. Ahora se ve de otra manera, nadie pone en duda que sea perjudicial. Nosotros hemos nacido con ese pensamiento".

-Renovación instituciones/monarquía: "Nuestra comunidad no ve mal que el príncipe se haya casado con una mujer separada. Es decir, que para nosotros el divorcio es una opción posible y normalizada".

-Brecha digital: "Nuestra comunidad no sufre la brecha digital como comunidades de otros países. Es decir, tenemos acceso a todas las nuevas tecnologías de la información y a través de ellas a multiplicidad de conocimientos."

-La religión: "Para nosotros el poder de la Iglesia ha disminuido, de manera que religión e Iglesia pueden ir separadas. Alguien que sea creyente no tiene por qué sentirse identificado con la institución de la iglesia".

\section{Conclusiones}

En la presentación teórica de la memoria estética aludíamos al hecho de que todo grupo comunicativo construye uno de los temas iconográficos de mayor exigencia social: la figura de la mujer. Ésta última estaría integrada en la memoria estética, así como también comentábamos que esta memoria estética sigue un ritmo de transformación constante debido a su construcción de época. Sujeto a este ritmo estaría los sentidos que configuran la figura de la mujer. Lo significativo de los ejemplos que ponían nuestros alumnos no se limita únicamente al hecho de que se hace alusión a lo cambiante de los cánones y estéticas femeninos sino que, en la actualidad, los jóvenes que participaron en nuestra práctica concedieron una mayor importancia a la estética y corporalidad masculina. En otra parte del texto, también hemos hecho una rápida alusión a la íntima relación que existe entre el imaginario social y los medios de comunicación, en tanto que éstos influyen en su transformación y configuración de nuevos sentidos. No obstante, en la práctica realizada se hace referencia a la influencia de las Nuevas Tecnologías en reiteradas ocasiones. Nuestros jóvenes, mucho más próximos al concepto de "nativos digitales", viven y reconstruyen su memoria estética y su sentido social "continuum" a través de las TIC. Incluso, tal y como hemos visto, definen su construcción identitaria en íntima relación con esas Nuevas Tecnologías.

Los resultados obtenidos aluden a la dificultad que tienen nuestros jóvenes en alcanzar una precisión epistemológica a la hora de explicar los elementos constitutivos de su imaginario social. Evidentemente, dicha precisión no se logra con una sola prác- 
tica, sino que requiere de una aprehensión de lecturas, y de una reiteración de prácticas en las que se pueda llevar a cabo este tipo de reflexión y construcción intersubjetiva. Del mismo modo que uno no alcanza a ser un gran músico en un par de clases, tampoco alcanza la concienciación de todas las implicaciones de su estructura identitaria. Lo importante es empezar a andar hacia esa dirección, teniendo como escenario general el imaginario social; en definitiva, redescubriendo los símbolos en nuestra vida cotidiana.

\section{Referencias bibliográficas}

ARIÑO, Antonio (1997): Sociología de la cultura: La constitución simbólica de la sociedad. Barcelona, Ariel Sociología.

CLIFFORD, James (1991): "Introducción: verdades parciales", en MARCUS, George y CLIFFORD, James: Retóricas de la Antropología. Madrid, Editorial Júcar.

FRESARD, Olivier (2005): "El imaginario social o la potencia de inventar de los pueblos". Revista Transversales, $\mathrm{n}^{\circ} 2$, primavera 2005.

\section{Carmen GAONA PISONERO}

Universidad Rey Juan Carlos de Madrid. Facultad Ciencias Comunicación

Profesora contratada doctora

carmen.gaona@urjc.es

\section{Juan-Francisco TORREGROSA CARMONA}

Universidad Rey Juan Carlos de Madrid. Facultad Ciencias Comunicación

Profesor contratado doctor

juanfrancisco.torregrosa@urjc.es 